\title{
Conciencia lingüística y cultural a través del léxico y la imagen: diccionario audiovisual bilingüe y bicultural FR-ES (BILBICAV)
}

\author{
Linguistic and cultural awareness through \\ lexicon and image: bilingual and bicultural \\ audiovisual dictionary FR-SPA (BILBICAV)
}

\author{
Gemma SAnz Espinar \\ Universidad Autónoma de Madrid \\ gema.sanz@uam.es \\ Aránzazu Gil CASAdomet ${ }^{1}$ \\ Universidad Autónoma de Madrid \\ aranzazu.gil@uam.es
}

\begin{abstract}
Bilingual education from early stages (Candelier \& Castelotti, 2013) has been developed in Europe over the last 30 years, which has led to the definition and study of multilingual and multicultural competence, the development of multilingualism didactics and complex concepts related to cultural competence (intercultural, metacultural, transcultural...). Within this framework, we propose to design a bilingual and bicultural French-Spanish visual dictionary that allows us to visualise the conceptual and cultural differences between the French and Spanish languages and cultures. Images, and specially pictures, for each word in each language, will develop awareness of linguistic
\end{abstract}

\begin{abstract}
Résumé
L'éducation bilingue dès les premières étapes (Candelier \& Castelotti, 2013) a connu un développement important en Europe au cours des 30 dernières années, qui a conduit à la définition et à l'étude de la compétence plurilingue et pluriculturelle, au développement de la didactique du plurilinguisme et de concepts complexes en relation avec la compétence culturelle (interculturelle, métaculturelle, transculturelle...). Dans ce cadre, nous proposons de concevoir un dictionnaire visuel bilingue et biculturel français-espagnol qui permette de visualiser les différences conceptuelles et culturelles entre les langues et cultures française et espagnole. Les images, plus précisément des photos, seront
\end{abstract}

1 Las autoras pertenecen al grupo de investigación LAEC Lingüistica argumentativa enunciativa y cultura francesa de la Universidad Autónoma de Madrid, HUM070 y a TILC\&COM Laboratorio de transferencia de conocimiento e innovación en ciencias del lenguaje y de la comunicación (IP: Marta Tordesillas).

Gema Sanz Espinar forma también parte del grupo Plurilingüismo y literatura transnacional en Europa ELITE HUM065. IP: Margarita Alfaro HUM065. Aránzazu Gil Casadomet pertenece asimismo al grupo Lingüística francesa, general y aplicada E023-09. IP: Mercedes Eurrutia Cavero, Universidad de Murcia. 
Anales de Filología Francesa, n. ${ }^{\circ}$ 29, 2021

CONCIENCIA LINGÜÍSTICA Y CULTURAL A TRAVÉS DEL LÉXICO Y LA IMAGEN: DICCIONARIO...

relativity (éveil aux langues) and cultural relativity (éveil aux cultures). A sound version will be added thanks to a digital format in order to create a French-Spanish BILingual and BICultural AudioVisual dictionary (BILBICAV FRES).

\section{Keywords}

bilingual and bicultural audiovisual dictionary, language awareness, cultural awareness, multicultural and multilingual competence, image. spécifiques et pourront être différentes pour les mots de chaque langue afin de développer la conscience de la relativité linguistique (éveil aux langues) et de la relativité culturelle (éveil aux cultures). Grâce à un format numérique, une version sonore sera ajoutée afin de créer un dictionnaire AudioVisuel BILingue et BICulturel français-espagnol (BILBICAV FRES).

\section{Mots-clés}

dictionnaire audiovisuel bilingue et biculturel, conscience linguistique, conscience culturelle, competencia plurilingüe y pluricultural, imagen.

\section{Introducción}

La educación bilingüe desde etapas tempranas en el sistema educativo (Infantil, Primaria, inicio de la Secundaria) ha tenido un amplio desarrollo en Europa en los últimos 30 años, lo que ha desembocado en la definición y estudio de la competencia plurilingüe y pluricultural (cf. Coste, Moore y Zarate, 1997; Consejo de Europa, 2002; Candelier \& Castellotti, 2013), en el desarrollo de la didáctica del plurilingüismo y de la pluri/interculturalidad ${ }^{2}$, así como de una compleja red de conceptos en relación con la enseñanza/aprendizaje de la lengua extranjera y de la cultura: competencia cultural, intercultural, metacultural, co-cultural, transcultural (cf. Puren, 2015).

La Didáctica de la lengua extranjera en el ámbito francés se ha posicionado hace tiempo como Didáctica de las lenguas-culturas extranjeras (DLC), dando un nuevo cariz a la concepción y a la relación entre ambas realidades. En ese marco, Galisson (1995) acuñó el término lexiculture, sobre todo en relación con la presencia de contenido cultural o el trasfondo cultural en las palabras, algo que algunos han aplicado directamente sobre la elaboración de diccionarios de lengua general (Guillén, 2003) o en diccionarios específicamente denominados "culturales (Rey, 2005) y que ha dado pie al llamado enfoque lexicultural, rebautizado como pragmática lexicultural (Attruia, 2010).

Según Puren (s.f.: 2), la DLC “est une discipline centrée sur l'observation, l'analyse, l'interprétation et l'intervention concernant les environnements, pratiques et processus situés et interreliés d'enseignement-apprentissage des langues-cultures" y en la disciplina está integrada la noción de lengua-cultura, propuesta por Galisson, aunque la posición que los distintos didactólogos tienen sobre dicha relación sea diferente, desde una posición fuerte ("l'apprentissage des langues comme instrument volontariste de défense des cultures et

2 Para los fines de este artículo no realizaremos distinción entre competencia pluricultural / competencia intercultural cuando hablemos de la competencia global competencia plurilingüe y pluricultural. 
d'intercompréhension entre cultures", Puren, s.f.: 4) hasta la versión débil ("un certain niveau de compétence communicative exige une certaine connaissance de la culture de ses interlocuteurs", Puren, s.f.: 4).

En el Volume complémentaire (Conseil de l'Europe, 2018) del Marco común europeo [MCER-CV], a la vez que se revisan tablas de descriptores de la competencia plurilingüe, se ahonda en la competencia intercultural y pluricultural, relacionándola con la macro-competencia de mediación, conceptos poco o nada desarrollados en el volumen del año 2002, que reflejan precisamente ese complejo polo de lo cultural al que hacíamos referencia. El MCERL-VC no es precisamente sencillo. De hecho, subsumir la competencia intercultural en la de mediación no facilita la tarea de crear objetivos operativos (en un grado de precisión y concreción útil para la integración en currículos y la puesta en práctica de las programaciones de curso). La herramienta teórico-metodológica más explícita hoy en nuestra opinión es el Marco de referencia para los estudios plurales de las Lenguas y de las Culturas (MAREP) o CARAP en sus siglas francesas (Candelier et al., 2013 [2007 para la versión francesa]). Y para los contenidos concretos (léxico específico), las obras de referencia serían los Référentiel de francés, en especial los de $\mathrm{A} 1$ a B232 , o el Plan curricular del Instituto Cervantes (AAVV, 2006) para el español.

Por otro lado, en relación con la competencia plurilingüe y pluricultural (CPP), el MCER (2002) indica que "una competencia plurilingüe y pluricultural que incluye todo el repertorio lingüístico del que se dispone" no es "un repertorio de competencias comunicativas diferenciadas y separadas dependiendo de las lenguas" (Consejo de Europa, 2002: 205). Ahora bien, ¿cómo se concreta esta interrelación externa entre la realidad-lenguas y la realidad-culturas?, ¿cómo se concreta dicha interrelación a nivel de la enseñanza y a nivel del aprendizaje o desarrollo de las competencias relacionadas con ellas? La comparación y cómo se haga cobra su importancia aquí. Como se dice en Neuner et al.:

Le monde personnel et l'expérience socioculturelle des apprenants, qui influencent leur conception de la vie, jouent également un rôle capital dans leur perception et leur évaluation des phénomènes socioculturels du monde étranger. Le monde de l'apprenant ne doit donc pas être exclu de l'enseignement des langues étrangères, il peut au contraire servir de référence dans le choix des thèmes et la définition des tâches. (Neuner et al., 2003: 54)

Nos interesa particularmente tratar dos nociones para acceder a una concreción de cara a la elaboración de un diccionario bilingüe, es decir, a la elaboración de una herramienta donde el contacto de lenguas y culturas está mediado por un formato que las separa y las acerca a la vez. Se trata de las nociones de conciencia (de la relatividad) lingüistica (éveil aux langues) y conciencia (de la relatividad) cultural (éveil aux cultures), que se basan en una cierta competencia reflexiva (en parte, metalingüística y metacultural) en torno a la idea

3 Beacco y Porquier, 2007 y 2008; Beacco et al., 2011a y 2011 b. 
de que las lenguas conceptualizan el mundo de manera diferente (los significados o conceptos expresados por las palabras no son absolutos) y de que las sociedades e individuos tienen culturas (modos de vida, valores, puntos de vista) diferentes. Como objetivos educativos, en Fenner \& Newby (eds., 2000), se puede ver para ambas nociones, una síntesis de objetivos, así como materiales para su enseñanza.

Para los fines de este artículo, entenderemos estas dos nociones como procesos y no como enfoques didácticos. En el caso de la expresión éveil aux langues, existe una metodología didáctica específica (traducida como despertar a las lenguas en Candelier et al., 2013: 8-9) enfocada, sobre todo, a los inicios de la educación bilingüe con el fin de poder tomar conciencia de la relatividad de las lenguas extranjeras y "allanar" el camino hacia su aprendizaje (Candelier \& Castelloti, 2013). Sin embargo, en nuestro caso, éveil aux langues lo entenderemos como los procesos de percepción o de conciencia (de la relatividad) lingüistica y el éveil aux cultures lo traduciremos como la percepción o conciencia (de la relatividad) cultural: toma de conciencia progresiva de que las lenguas y las culturas no son equivalentes o simétricas. Teniendo en cuenta que el formato del diccionario bilingüe suele dar pie a una ficción de simetría, es nuestro principal propósito que dicho formato sea revisado y adaptado a nuestro presupuesto inicial: la relatividad lingüística y cultural y a nuestro propósito de visibilizarlas.

Teniendo en cuenta, por otra parte, la complejidad de los objetos lengua y cultura, no se puede dar por supuesto que la toma de conciencia de esta relatividad sea solo una experiencia necesaria en el inicio del aprendizaje de una lengua-cultura extranjera, sino que esta percepción será progresiva en un proceso de adquisición paulatina de las especificidades y diferencias entre las lenguas-culturas maternas y extranjeras (Candelier et al. 2013; Sanz Espinar, 2021).

Ahora bien, como no deja de ser importante que estas competencias se desarrollen desde los niveles iniciales del aprendizaje de la lengua ligada a la conciencia de las diferencias culturales, muchas de las cuales se codifican en el léxico más básico y corriente, nuestro primer objetivo ha sido abordar la concepción y diseño de un diccionario BILingüe y BICultural AudioVisual (BILBICAV) español-francés para España-Francia comenzando por el nivel A1 del MCER, centrándonos en el vocabulario de la ropa y de la comida poniendo de manifiesto las diferencias culturales detrás de las palabras. Seguimos en esto el modelo del "diccionario de un país" como lo llama Ferrara (2009), aunque, en este caso, no solo se trata solo de una lengua sino de dos, y no solo de dos lenguas, sino de la cultura de dos países.

Así, trataremos casos como déjeuner-comida, y convendrá precisar que el déjeuner culturalmente tiene lugar hacia las 12:00-14:00 en Francia, frente a la comida del mediodía que en España tiene lugar aproximadamente entre 13:30-16:00; así como midi y mediodía no equivalen pragmático-culturalmente. Por otro lado, si en la enseñanza del léxico de la ropa en francés a un estudiante español se le indica una correspondencia entre chemise-camisa, se 
propicia una simplificación de la realidad lingüístico-cultural cotidiana dado que una camisa o blusa, si es para mujer, puede corresponder a varios conceptos en francés como chemisier, mientras blouse corresponde más a bata de trabajo, o blusa, o especialmente con el sentido de "blusa de seda". Algo similar ocurre entre gilet y chaleco/chaqueta de lana, refiriéndose gilet a prendas de lana con botones mientras que la oposición entre el chaleco y la chaqueta en español se basa en tener o no mangas. Hay que recordar que los términos camisa, chaqueta, chemise o veste aparecen en nivel A1 para francés en Beacco \& Porquier (2007) y, para el español, en el Plan curricular del Instituto Cervantes (AAVV, 2006) pero la complejidad indicada, el trasfondo cultural, no siempre se traslada en los métodos de lengua, por ejemplo. ¿Hasta dónde profundizar?

Sobre esta base de concepción del léxico, nuestro interés es aprovechar metodologías actualmente disponibles en lexicografía y terminología para tratar el léxico no solo de manera aislada sino también de modo contrastado y como parte de sistemas lingüístico. En este tipo de producto lexicográfico se visualizaría desde el primer momento el tándem lenguacultura, la proximidad semántica entre palabras de las dos lenguas y a la vez las diferencias pragmático-culturales entre ellas. Para facilitar la comprensión de este contraste, nos apoyaremos en la imagen, priorizando las fotos antes que los dibujos, para evitar simplificar el significado y el contexto, con el fin de mostrar las particularidades de las realidades a las que se aplican estas palabras en las distintas sociedades. En este sentido, la imagen aporta elementos de la "referencia" extralingüística a la que se remitiría el "signo lingüístico". Por esta razón, asumiremos que, en principio, no siempre servirá la misma imagen para cada par de palabras lengua origen (LO) - lengua meta (LM), sino que buscaremos que cada imagen corresponda con realidades de una sociedad u otra imagen para reflejar estos elementos de contraste. Del mismo modo, tampoco necesariamente el diccionario es simétrico. Así, la dirección en la dirección español $>$ francés podrá aparecer la entrada paella y su traducción paella, en francés, pronunciado/paela/) pero no en la dirección francés>español (donde no tiene sentido introducir esta entrada desde el francés). Dicho esto, teniendo en cuenta que no todos los elementos culturales son de naturaleza visual, recurriremos también a notas semánticas o culturales para explicitar lo que sea necesario mediante el lenguaje. Y, por último, podrá haber artículos sinópticos (Leroyer \& Bergenholtz, 2013) con dibujos, esquemas o mapas conceptuales que asocien diversos elementos de léxico, por ejemplo, CUBIERTos, que asocien tenedor, cuchillo, cuchara. De este modo, llevamos al extremo los presupuestos teóricos en relación con la relatividad lingüística y cultural, trabajando en otra modalidad de lo que en Sanz Espinar, (2020) se llama mesoestructura, interfaz de un diccionario bilingüe que pone en comunicación y contraste las palabras, tanto mostrando una frontera de contacto no simétrico entre las palabras de las dos lenguas como diferenciando palabras de la misma lengua como parte de un sistema léxico-conceptual diferente.

Por último, la elaboración de este diccionario ejemplifica una metodología transferi- 
Anales de Filología Francesa, n. ${ }^{\circ}$ 29, 2021

CONCIENCIA LINGÜÍSTICA Y CULTURAL A TRAVÉS DEL LÉXICO Y LA IMAGEN: DICCIONARIO...

ble para la presentación del léxico en un enfoque contrastivo y plural integrador en el aula de francés como lengua extranjera en contexto educativo español o viceversa.

\section{La cultura, objeto de enseñanza/aprendizaje complejo}

Cultura, lengua-cultura, lexicultura, competencia cultural o intercultural, pluricultural..., visto desde la Didáctica de Lenguas-Culturas Extranjeras, el objeto se vuelve cada vez más complejo. Desborda de facto la clase de Lengua Extranjera, pero también es verdad que, desde un enfoque de Didáctica del plurilingüismo, se propone una transversalidad.

La antropología define "cultura" como aquello que forma parte del conocimiento humano y que no es innato sino aprendido. Ahora bien, según algunas teorías actuales sobre la relación entre lo innato y lo aprendido, ambos están muy imbricados (las capacidades innatas son necesarias para aprender, e inversamente, algunas investigaciones demuestran cómo lo aprendido se registra en el ADN). Por otra parte, la cultura se asocia a veces a grandes grupos humanos y ciertos rasgos comunes y homogéneos, pero cuando se entiende por cultura el conjunto de valores, creencias, representaciones, hábitos, comportamientos, etc. podemos descender hasta el nivel del individuo, ya que cada individuo tendrá un conjunto de ellos propio que le puede hacer entrar en conflicto con otro individuo (familiar, allegado, externo al grupo familiar). Lo mismo encontramos en el concepto lengua (producto cultural en sí mismo) pues encontramos características en un rango que va desde lo común a un grupo hasta lo idiosincrásico de un estilo propio de habla del individuo.

En la enseñanza de la lengua extranjera, la cultura tiene un estatuto variable y no estable. Así, en el nivel universitario a menudo se concibe una materia independiente de tipo Civilizacion / Cultura de la lengua extranjera (Rossignol, 2000). Ahora bien, en el marco de una lengua-cultura, se trata de abordar la cultura en su relación con la lengua.

Por otro lado, se ha ido desarrollando un concepto de competencia cultural muy complejo con distintos componentes, así como de "competencia pluricultural", que no se entiende como una suma de conocimientos culturales inconexos. En la línea del MCER, Neuner et al. (2003) o Byram et al. (2002) tratan de delimitar un doble objeto de estudio: competencia cultural como contenido sociocultural y competencia intercultural como capacidad para ver el mundo extranjero. Durante un tiempo se ha discutido sobre todo esta oposición a raíz del planteamiento que el MCER realizaba poniendo en primer plano la competencia intercultural como saber hacer. Ahora bien, el objeto cultura y su tratamiento requieren de un enfoque más complejo por la realidad, también más compleja, a la que remiten. Así, Puren (2015) propondrá varios componentes de la competencia cultural: pluricultural (capacidad para convivir en harmonía en una sociedad multicultural con personas parcial o totalmente diferentes), intercultural (capacidad para identificar los malentendidos o la falta de entendimiento en primeros contactos o contactos puntuales), transcultural (capacidad para reconocer en los 
textos clásicos un fondo común, lo humano más allá de la diversidad de manifestaciones culturales), metacultural (capacidad para hablar sobre la cultura a partir de los conocimientos o crear nuevos conceptos a partir de la observación, lectura de textos auténticos...), co-cultural (actuar con el otro de manera a conseguir un proyecto vital conjunto; creación de una cultura compartida).

Esta complejidad nos lleva no solo a reflexionar sobre la complejidad de su enseñanza/aprendizaje, sino lógicamente también de su evaluación. En este sentido, hemos de destacar la aportación del Marco de referencia para los enfoques plurales, MAREP, en español (CARAP, en francés), para una concreción de objetivos. Sin un nivel de concreción adecuado, el objetivo global, demasiado complejo, no permitirá hacer una planificación educativa adecuada y así como Candelier et al. (2013: 7) hablan de que el plurilingüismo ha de ser objetivo de todas las materias implicadas en una sección bilingüe es decir, un "cambio de paradigma principal que está en la base de la evolución hacia una concepción global de la educación lingüística, que integra la enseñanza y el aprendizaje de TODAS las lenguas, para utilizar las sinergias potenciales", también habrá que comprender que lo mismo se aplicará a la cultura, por ser un objeto de amplias dimensiones.

Para el profesor de lenguas extranjeras la tarea se va complicando y, para ayudar a desarrollar la competencia pluricultural, proponemos la siguiente descripción de la "competencia para enseñar cultura" en relación con la lengua:

- Conocer, comprender y poder manipular el objeto que se ha de enseñar: la cultura francesa y francófona en contraste al menos con la propia cultura y con otras conocidas e integrando los conocimientos de manera creativa. En este sentido, los conocimientos de diversas culturas podrían derivar en visiones particulares del mundo.

- Conocer, comprender y ser capaz de observar de manera objetiva, de analizar y de evaluar cualitativa y cuantitativamente un proceso de adquisición de saberes y de competencias (saber-hacer) en relación con la competencia pluricultural (enfoque de lenguas-culturas extranjeras).

- Conocer y saber aplicar diferentes metodologías de enseñanza específicas para ello y en contexto de plurilingüismo (enfoques plurales, integrados...).

Por último, como indica Grosjean $(2015,2018)$ será necesario darse una definición mucho más afinada de la "persona bilingüe y bicultural", donde no solo se trata de conocimientos culturales, sino también de habilidades, integración de culturas y reconocimiento propio o externo de dicho estatuto, entre otros niveles, dado que se da la circunstancia, como con las lenguas en la persona bilingüe, de una cultura dominante o de una cultura más reconocimiento propio o externo que otra. Esto no podrá conseguirse sino a partir de un trabajo colectivo dentro del ámbito cultural, social y/o educativo. 


\section{Diccionarios visuales y/o ilustrados}

El término de "diccionario ilustrado" parece asociado al de una imagen, sin embargo, encontramos algunos "diccionarios ilustrados" que "ilustran" los conceptos de las palabras con "texto". Es el caso del Vocabulaire de la ville expliqué et illustré [VVEI]. Véase la siguiente entrada:

\section{Amendes}

Le produit des amendes de police est reversé en partie de l'Etat aux communes. Il est destiné à financer les travaux d'amélioration des transports et de la circulation.

Pour chaque commune, le produit des amendes est fonction de la valeur d'un « point ", périodiquement révisé ${ }^{1}$.

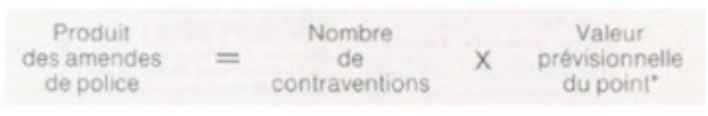

Imagen 1. Entrada amendes en el Vocabulaire de la ville expliqué et illustré (Arnaud, 1992: 20).

Por otro lado, el término de "diccionario visual" parece más claro y preciso, aunque hay una serie de variaciones posibles: de una o varias lenguas, con presencia de dibujos vs. fotos, de términos de un área específica de especialidad vs. de palabras de la lengua general.

Existen una serie de características que describen los diccionarios ilustrados:

- diccionario ilustrado (entendiendo, ilustrado con textos)

- diccionario visual monolingüe (fotos o dibujos)

- diccionario visual bi/plurilingüe (misma imagen para las 2 palabras): normalmente incluyen diversos índices alfabéticos para encontrar la palabra según las distintas lenguas

- diccionario en papel vs. digital (con características muy específicas)

- diccionario para niños vs. para adultos (con distinta selección de las palabras)

- diccionario técnicos o temáticos vs. diccionarios de lengua general

- diccionario visual vs. imagiers, imaginarios o flash-cards (listados o minigrupos semánticos o situaciones pragmáticas)

- diccionario visual (donde la imagen sería lo central) vs. diccionario de lengua y temáticos o especializados con información visual (enciclopedias, bases de datos terminológicas, cartillas para el aprendizaje de la lectura, métodos de lengua con base visual)

- $\quad$ interactividad posible con el diccionario (leer/escuchar; hipervínculos; diccionario directo o inverso). 
En la DLC, la cultura extranjera se puede contemplar desde dos ópticas: por un lado, como contenidos socio-culturales sin más, o como lengua-cultura extranjera. Ahora bien, Galisson propone el concepto de lexicultura: "la culture mobilisée et actualisée dans et par les mots de tous les discours dont le but n'est pas l'étude de la culture pour elle-même" (1995: 6). Este enfoque permite incluir el nivel cultural en la lengua, contar con que la lengua de hecho ya es un producto cultural en sí mismo.

Attruia (2010) indica qué elementos podrían ser visibilizados en un diccionario monolingüe de uso como el Petit Robert. Con el fin de pensar el modo de trasladar este conocimiento cultural inscrito en la lengua, y en particular en el léxico, al diccionario, Attruia precisa cómo, desde la pragmática lexicultural, se amplía la dimensión pragmática (en sentido extenso) de las palabras, de su uso en contexto y de su carácter compartido (charge culturelle partagée de Galisson). Pone así en entredicho un concepto elitista de cultura e introduce la "variación”, pasando de un concepto único y hegemónico a una dualidad antagónica: cultura culta vs. la cultura viva y compartida en su deseo de expandirse y tomarlo todo. Quizás, en nuestro caso, no nos resulta necesario hacer la distinción; llegado el caso, ambos casos son cultura.

Attruia (2010) señala como parte del conocimiento lexicultural:

- conocimiento enciclopédico

- nombres propios

- mots à charge culturelle partagée (CCP)

- eufemismos

- mots valises (composiciones) y lexicalizaciones a partir de acrónimos ipod, email, etc.

- $\quad$ interjecciones y onomatopeyas, a menudo en expresiones.

Los elementos culturales en el BILBICAV tendrán en cuenta algunos otros elementos culturales en relación directa o tangencial con la lengua como pueden ser: los nombres propios (tiendas, marcas de comida o de ropa), la propia configuración del conocimiento en micro-sistemas o microcampos semánticos con particularidades en cada lengua y país, como, por ejemplo, qué forma parte de un desayuno francés o español, o el horario de comidas a lo largo del día asociado a las costumbres o al horario solar. Asimismo, el hecho de que algunas palabras no tengan "traducción" y que haya que utilizar un préstamo, pero corresponden a una realidad española pero no francesa. También podrán formar parte los estilos de ropa habituales en Francia vs. en España independientemente de las tendencias internacionales de moda e incluso las adaptaciones de las multinacionales a los países precisos (Burger King en Francia vs. Burger King en España; Carrefour en Francia, Carrefour en España, ¿dónde se perciben las diferencias?). 
Anales de Filología Francesa, n. ${ }^{\circ}$ 29, 2021

CONCIENCIA LINGÜÍSTICA Y CULTURAL A TRAVÉS DEL LÉXICO Y LA IMAGEN: DICCIONARIO...

\section{Un diccionario audiovisual bilingüe y bicultural (BILBICAV) francés-español}

El diccionario BILingüe y BICultural AudioVisual (BILBICAV) francés-español es un diccionario que plantea mostrar el contraste entre las lenguas-culturas con ayuda de imágenes, hasta donde sea posible, como ya adelantábamos.

Es habitual confeccionar diccionarios visuales multilingües con una sola imagen común para las diferentes lenguas, así como una sola opción de palabra o locución por cada lengua para cada imagen. Sin embargo, el objetivo de este diccionario es mostrar la relatividad lingüística y la relatividad cultural: cada lengua es diferente, cada cultura es diferente. Así, este diccionario tiene dos partes, dos direcciones: una, francés-español y otra, españolfrancés. El repertorio de palabras francesas del nivel A1 del Marco común europeo de referencia (para todos los públicos), tendrá equivalentes de traducción en español que no forman parte del nivel A1 para el español y viceversa. La doble dirección del diccionario permitirá visibilizar mejor esta circunstancia. Por otro lado, damos espacio si es necesario a varias acepciones y a varias traducciones posibles para una misma palabra.

En lo relativo a la imagen, cada par de palabras francés-español tendrá sus propias imágenes. Esto evitará la idea de que los pares de palabras francés-español son "simétricos" (mismo sentido, mismas implicaciones, mismas connotaciones, mismos referentes, mismas imágenes para representar esos referentes).

La cultura está, en efecto, en las palabras, pero la cultura se ve, se oye, se vive, toma forma fuera de la lengua, a veces antes de estar presente en la lengua. Y cada lengua refleja la cultura "a su manera". Observaremos por tanto que no reducimos a una la imagen asociada a cada palabra. La cultura francesa y española no son culturas uniformes, de modo que proponemos imágenes que reflejan la diversidad interna de "la" cultura francesa y de "la" cultura española, en un enfoque plural e intercultural fuerte. Nos parece importante poner de manifiesto esta diversidad de cara a desarrollar la conciencia de la lengua y la conciencia de la cultura, huyendo de los estereotipos.

En el BILBICAV, las palabras tienen forma escrita y oral, definición(es), un ejemplo escrito y varias imágenes que representan los posibles referentes reales de las palabras. Estos objetos y situaciones, diferentes en cada cultura, serán representados por imágenes, en especial fotos, para mostrar mejor las especificidades culturales, en este caso, de Francia y España (Neuner, 2003; Muller, 2012). Las entradas se completarán con notas culturales cuando sean necesarias para esclarecer aspectos culturales o semánticos de las palabras. Además, el BILBICAV propone una versión oral de las entradas y una descripción breve de cada imagen con vistas a facilitar la accesibilidad de la herramienta y una explotación pedagógica para el aprendizaje oral de las lenguas (texto correspondiente a la metaetiqueta de html ALT).

Por último, el vocabulario no se presenta solo alfabéticamente. Se podrán encontrar fichas de vocabulario (artículos sinópticos), mapas conceptuales e imágenes globales o de 
situación para poner en relación subconjuntos de palabras, así como ideas para la explotación pedagógica.

En el Cuadro 1 describimos la particularidad del diseño y conceptualización del diccionario en base a sus objetivos, para mostrar después el diseño formal (apartado 4.3).

\section{ÍTEMS PARA EL DISEÑO DE UN DICCIONARIO VISUAL TEMÁTICO}

Texto/Imagen

(T, I, T-I)

\section{Lenguas}

(Mono-, Bi-, Pluri-) y lengua principal. Índices por lenguas

\section{Edad}

\begin{tabular}{c}
\hline Edad \\
\hline Macroestructura (cantidad, temática) \\
\hline $\begin{array}{c}\text { Acceso a palabras: índice alfabético, } \\
\text { por imágenes globales situacionales, } \\
\text { por subtemas }\end{array}$
\end{tabular}

Especializado/General

Tipo de imagen: Foto, foto de situación, dibujo aislado, dibujo de situación, cuadro, gráfico, icono, esquema, artículos sinópticos.

\section{BILBICAV}

Texto escrito, audio e imagen.

Las imágenes serán con "carga cultural” y tendrán un texto alternativo (tanto para atender la accesibilidad, como para comprender que el referente al que se remite la palabra puede ser diferente: no es lo mismo la idea de midi que de mediodía).

Bilingüe. Con doble dirección alfabéticamente ordenada: FR $>$ ES y ES $>$ FR. Asimétrico.

La imagen no favorece la idea del concepto único con dos significantes diferentes.

Todas las edades. Distintos tipos de explotación posibles.

Palabras básicamente del Reférentiel pour le

français A1 y del Plan curricular del Instituto

Cervantes con alguna ligera adaptación.

Índice alfabético.

Imágenes globales o de situación.

Mapas conceptuales

Otros recursos para la representación del conocimiento temático del área: clasificación similar a los Référentiels y al Plan curricular del Instituto Cervantes.

Temática específica, pero no especializada: alimentación, ropa en una primera versión (nivel básico A1 del MCER)

Preferiblemente fotos, acompañadas de texto (acepciones y notas culturales). También esquemas, mapas conceptuales o dibujos, en la medida en que la foto no pueda reflejar ciertas relaciones o especificidades.

Formato 


\begin{tabular}{cl}
\hline $\begin{array}{c}\text { ÍTEMS PARA EL DISEÑO DE UN } \\
\text { DICCIONARIO VISUAL TEMÁTICO }\end{array}$ & BILBICAV \\
\hline $\begin{array}{c}\text { Función del diccionario (LM, LE, Espe-- } \\
\text { cialistas, Traductores) }\end{array}$ & $\begin{array}{l}\text { Desarrollo de competencia plurilingüe y plu- } \\
\text { ricultural en la propia lengua y en lenguas ex- } \\
\text { tranjeras. }\end{array}$ \\
\hline $\begin{array}{l}\text { La imagen estará subordinada al concepto y } \\
\text { tratará no solo de ilustrar el significado del } \\
\text { concepto que pueda ser distinto en cada equi- } \\
\text { respecto del texto (lateral de una imagen de la imagen: localización } \\
\text { global/flechas, flash-card (memory } \\
\text { card))... }\end{array}$ & $\begin{array}{l}\text { valente parcial en Francés y en Español, sino } \\
\text { a los referentes de ambos países: p.ej., imagen } \\
\text { de una panadería española o francesa (rótulos } \\
\text { singulares de las tiendas). }\end{array}$ \\
\hline
\end{tabular}

Definición

\begin{tabular}{ll} 
Definición & cisa de las distintas acepciones de la palabra. \\
& En las imágenes de conjunto se hará especial \\
& hincapié en las diferencias entre los objetos. \\
\hline Nota cultural & En las notas culturales se especificarán ele- \\
& mentos espaciales, temporales, asociaciones, \\
& valores, ideologías, puntos de vista, aconteci- \\
& mientos propios del país, etc. que puedan ser \\
& necesarios no solo para comprender, sino tam- \\
& bién para utilizar adecuadamente las palabras \\
& en un contexto dado. \\
\hline
\end{tabular}

Cuadro 1. Conceptualización del diccionario BILBICAV para francés-español.

El diseño de los distintos niveles estructurales del diccionario: macroestructura, mesoestructura y microestructura.

\subsection{Macroestructura del diccionario}

Llamaremos macroestructura al conjunto de ítems que recoge el diccionario tanto cualitativa como cuantitativamente (qué palabras y cuántas).

Es raro que los diccionarios visuales contengan una introducción a la obra clara que explicite la selección de palabras y la temática. De hecho, los títulos de los diccionarios son lo más parecido a dicha explicitación: contienen a menudo la temática y/o la lengua; junto con esto, el tipo de imagen que contienen puede facilitarnos la identificación de si se trata de un diccionario para público infantil o juvenil vs. adultos (más afín a dibujos en el caso de público infantil, aunque no necesariamente). 
En nuestro caso, el título completo Diccionario audiovisual bilingüe y bicultural español-francés (BILBICAV) para España y Francia (Ropa y alimentación, nivel A1 MCER), indica ya los elementos clave, ahora bien, los retos a los que quiere atender y objetivos a los que quiere llegar se presentarán en una introducción con ejemplos de entradas-tipo.

Para el nivel A1 del MCER campos de la alimentación y de la ropa hemos extraído un listado del vocabulario del nivel A1 en francés y en español del Référentiel Al (2007) y del Plan curricular del Instituto Cervantes (2006) en los campos de la ropa y la alimentación, cruzándolos y extrayendo un listado propio para el español y otro para el francés. Precisemos, por un lado, que los listados temáticos que contienen no son completamente cerrados en ningún nivel, pues se dejan abiertos ciertos subgrupos. Sin embargo, pueden servirnos para establecer la base de la macroestructura. Por otro lado, tampoco son "simétricos". Para subrayar la no simetría de la lengua-cultura, prevemos dos direcciones independientes FRES y ES-FR. En cuanto a las modalidades de ordenación y búsqueda, el diccionario tendrá un formato en un primer momento de tipo libro digital, de modo que las entradas bilingües se ordenarán alfabéticamente en una dirección rigiéndose por la lengua de entrada: lengua de origen $1>$ lengua meta $1\left(\mathrm{LO}_{1}>\mathrm{LM}_{1}\right)$ en un sentido y lengua de origen $2>$ lengua meta 2 $\left(\mathrm{LO}_{2}>\mathrm{LM}_{2}\right)$.

En Sanz Espinar (2004) ya tratábamos la “(a)simetría” en el diccionario bilingüe general. Reconocer la "asimetría" conceptual, nos condiciona a la hora de seleccionar las entradas en el diccionario visual en la dirección FR-ES o bien ES-FR. Es decir, la palabra tapas podrá formar parte del diccionario en el diccionario ES-FR como palabra del nivel A1, traducida a su vez como tapas en francés (con su pronunciación a la francesa, eso sí), la dejamos fuera en el caso del diccionario FR-ES.

Se añade a esto la inclusión de nombres propios preferiblemente dentro de las distintas fichas (nombres de marcas de ropa, etc.).

\subsection{Ordenación dentro del diccionario: la mesoestructura}

Se crearán distintos tipos de navegación alfabética y semántica mediante cruces y representaciones del conocimiento (relaciones o cruces semánticos).

Dado que el índice alfabético no permite construir por sí solo una red semántica que facilite el aprendizaje de distintas palabras relacionadas entre sí pragmática o semánticamente, para el desarrollo de la mesoestructura se trabajará por dos vías: vía el "significante" y el "significado" (por ejemplo, con palabras organizadas en campos semánticos y mediante mapas conceptuales) y vía la "pragmática cultural” (por ejemplo, con imágenes de situación, que vinculen distintos conceptos entre sí: la mesa, en el sentido de "la mesa puesta"). Esto permite navegar de la idea a la palabra y de la palabra a la idea y también de la situación o conocimiento cultural a la palabra y viceversa. 


\subsection{Microestructura}

Llamaremos microestructura a la información que se incluye en un artículo del diccionario.

En el caso de los diccionarios de lengua ilustrados, la microestructura puede ser más variada, pues originariamente son diccionarios generales con texto a los que se añade aquí y allá alguna ilustración. En el caso de los diccionarios visuales, la información lingüística presente suele ser muy "básica": además de la imagen, aparece la palabra o término para referirnos a dicho tipo de referencia extralingüística, su traducción y, eventualmente, en el caso de diccionarios bilingües puede aparecer información sobre el género (como en muchos diccionarios visuales plurilingües).

El BILBICAV busca una interfaz o mesoestructura ( $c f$. Cuadro 2) que a la vez sirva de "lugar de encuentro", a la par que de "frontera" y "lugar de diferenciación" de los conceptos y los significantes, proporcionando, además, un acceso a los referentes plausibles y preferiblemente culturalmente determinados. Todo ayuda: imagen, texto escrito y sonoro.

\begin{tabular}{|c|c|c|}
\hline \multicolumn{2}{|l|}{ Doble página } & Información proporcionada \\
\hline $\begin{array}{c}\text { PALABRA FR } \\
\text { (+ vínculo al audio) }\end{array}$ & $\begin{array}{c}\text { PALABRA ES } \\
\text { (+ vínculo al audio) }\end{array}$ & significante escrito y oral \\
\hline $\begin{array}{c}\text { Género } \\
\text { (y número si es necesario) }\end{array}$ & $\begin{array}{c}\text { Género } \\
\text { (y número si es } \\
\text { necesario) }\end{array}$ & morfología \\
\hline Foto FR o fotos FR & Foto ES o fotos ES & $\begin{array}{l}\text { aspectos semánticos y cultu- } \\
\text { rales visuales }\end{array}$ \\
\hline Nota semántica & Nota semántica & $\begin{array}{c}\text { aspectos semánticos explicita- } \\
\text { dos redactados }\end{array}$ \\
\hline $\begin{array}{l}\text { Nota cultural } \\
\text { - coordenadas espacio-temporales } \\
\text { amplias y específicas (regiones, } \\
\text { épocas) } \\
\text { - coordenadas socio-lingüísticas } \\
\text { - coordenadas ideológicas } \\
\text { - coordenadas regionales }\end{array}$ & Nota cultural & $\begin{array}{l}\text { aspectos pragmático-cultura- } \\
\text { les explicitados redactados }\end{array}$ \\
\hline $\begin{array}{l}\text { Vínculos a imágenes de situación o } \\
\text { mapas conceptuales }\end{array}$ & $\begin{array}{l}\text { Vínculos a imáge- } \\
\text { nes de situación o } \\
\text { mapas conceptuales }\end{array}$ & \\
\hline
\end{tabular}

Cuadro 2. Microestructura del BILBICAV. 
Desde el punto de vista de los perfiles de aprendizaje, el tipo "visual" parece verse más favorecido con una mayor presencia de la imagen. Ahora bien, la capacidad para la comprensión de imágenes es relativamente generalizada y tampoco debemos dar por supuesto que cualquier imagen se presta automáticamente a un solo tipo de construcción de sentido o de comprensión. Hay que recordar que en el BILBICAV las imágenes son ejemplificaciones y que no limitan las opciones de "referentes". Los ejemplos y las notas pueden ampliar las opciones proporcionadas por las imágenes. Es decir, hemos de adoptar a nuestro juicio un enfoque cognitivista que tome en cuenta el concepto de "comprensión" mediada de un concepto a través de la imagen. Es ahí, donde el texto tendrá también una función de precisión y de visibilización de los elementos contrastados en cada caso: texto alternativo descriptivo equivalente a la etiqueta ALT que señala qué aspectos de la imagen deben ser identificados prioritariamente, que permite además cuidar la accesibilidad, con una versión audio del mismo. Veamos pues un ejemplo de la microestructura FR $>$ ES.

$$
\text { petit déjeuner }{ }^{\mathrm{i}}(\mathrm{m} \text {. sing.) }(0))
$$
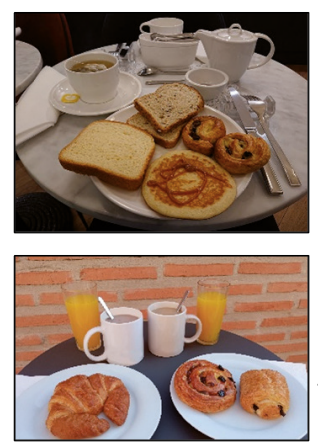

2. Du café au lait, du chocholat chaud, du jus d'orange, des viénnoiseries (un croissant, un pain aux raisins, un pain au chocolat).

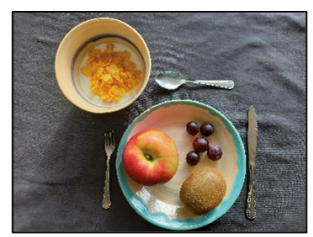

3. Des céréales avec du yaourt et des fruits.

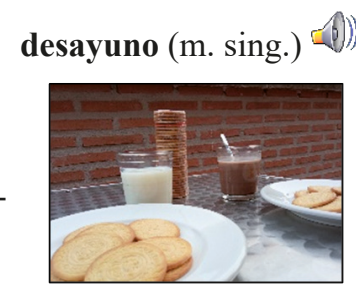

1. Leche con galletas.

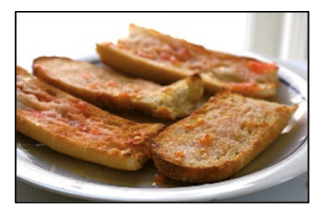

2. Barritas de pan con aceite de oliva $y$ tomate.

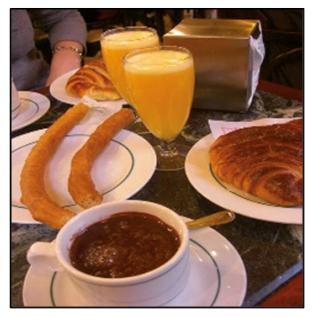

3. Zumo de naranja y chocolate con porras.

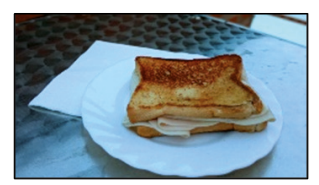

4. Sándwich mixto.

i Vínculos a las fuentes de las imágenes insertos: $<$ https://commons.wikimedia.org $>$. Cuando no hay hipervínculo la foto es de creación propia. 
Définition: Repas du matin. Le premier re- Definición: Comida de la mañana. La primepas du jour. ra del día.

Note culturelle: Le petit-déjeuner peut être Nota cultural: Los desayunos pueden ser assez varié avec des boissons chaudes (café, variados: bebida caliente (café, té, cacao) thé, chocolat chaud) et des viennoiseries ou con tostadas o cereales con leche o yogur, des tartines (tranche de pain grillé ou non algo de bollería (madalenas) o galletas. En recouverte de beurre ou de confiture), soit las cafeterías, es frecuente el sándwich mixdes céréales avec du lait ou du yaourt, entre to o las barritas con aceite de oliva y jamón autres.

o tomate. También el chocolate espeso con

Exemple: Comme petit-déjeuner, je prends un café au lait et des tartines.

churros o porras. En España a veces se desaVoir: Fiche Repas de la journée. yuna poco y se toma un almuerzo hacia las 10:30-11:00 (un pincho o un bollo y un café, por ejemplo). En España no es raro mojar las galletas en la leche.

Ejemplo: De desayuno, tomo cereales con leche.

Ver: Ficha Comidas del día

\section{Explotación de un BILBICAV en el aula de FLE}

El BILBICAV pretende colmar una laguna importante en los recursos basados en la imagen para lenguas extranjeras, ya que hoy día la búsqueda de fotografías para el profesor no deja de ser un problema debido, por un lado, a los derechos de imagen y, por otro, a los sesgos culturales y lingüísticos que presenta la búsqueda en motores como google. Algunos de los repositorios de libre uso de fotografías facilitan la tarea al profesor de crear diccionarios visuales ad hoc, pero los motores de búsqueda, entre otros el de Google parecen utilizar ontologías (redes semánticas predefinidas) que en una búsqueda básica de tipo "maison"+"France" devuelve resultados de imágenes relativamente parecidos a la búsqueda “casa"+"España". Se percibe pues un sesgo acultural o una homogeneización en base a un diccionario de palabras clave basado en una sola lengua, probablemente el inglés. Solo una búsqueda del tipo "maison typique France" empieza a tener cierto éxito a la hora de diferenciar culturalmente las fotos y por ende los referentes (Proulx, 2016). Por otro lado, podemos hacer referencia a la base de datos de comparada de imágenes de google en distintos países de Simon \& Swarts (2012), Image Atlas, que, aunque en la línea de lo que proponemos, está mediada por la lengua de búsqueda (solo el inglés). Constatamos algún problema con el etiquetado de la lengua ( $c f$. resultados de bread para Francia, donde se confunde pain en inglés "dolor, con pain, en francés, pan). El BILBICAV es un recurso que explicita la metodología de creación, con vistas a ser una metodología exportable o transferible. Por ello, nuestra 
recomendación es que las redes de profesores de distintos países construyan colectivamente repositorios de fotos de primera mano ${ }^{4}$ compartidos, utilizando un etiquetado específico (lugar, fecha, palabras clave y "palabras" con correcto etiquetado de palabra + metaetiqueta de la lengua en relación con la imagen que la representa) como base para una enseñanzaaprendizaje de la competencia plurilingüe y pluricultural.

Creemos que este recurso sería útil en el marco de los Enfoques plurales de lenguas y culturas, definidos por el MAREP (Candelier et al., 2013) entendiendo los "enfoques plurales" como aquellos “enfoques didácticos que ponen en práctica actividades de enseñanzaaprendizaje que implican al mismo tiempo a varias (más de una) variedades lingüísticas y culturales" (2013: 5-6). Por ello, las actividades del nivel A1 pueden incluir también, por ejemplo, comparativa con el inglés o búsqueda de anglicismos en español y francés, o de galicismos en español e inglés o de hispanismos en francés e inglés.

A continuación, indicamos algunas propuestas de explotación pedagógica para este diccionario:

1. El BILBICAV como herramienta complementaria para la comprensión de textos. Utilizar el BILBICAV como diccionario clásico para ayudar en la lectura de un texto. Comparar la comprensión de un texto con un diccionario normal y la comprensión con el BILBICAV. ¿Qué cambia?

2. El BILBICAV como ejemplo. Crear distintos tipos de entrada en tu propio diccionario audiovisual con fotos o imágenes diversas sobre un campo semántico preciso.

3. El BILBICAV cooperativo. Enviar e intercambiar fotos a una red de intercambio de fotos entre profesores.

4. Aprender a hacer mapas conceptuales, con herramientas informáticas gratuitas en línea o en papel.

5. Ampliar los mapas conceptuales propuestos en el diccionario con nombres propios de marcas o empresas de cada país: tiendas (Galeries Lafayette, Monoprix, El Corte Inglés, Zara), restaurantes (Rodilla, Hippopotamus, Pomme de pain, Starbucks), marcas de bebidas (Schweppes, Trina, Orangina), denominaciones de origen de productos alimenticios (Côtes-du-Rhône, emmental, baguette).

6. Inventar una pequeña historia en lengua extranjera o materna sobre una situación cómica o no tan cómica (en una tienda o supermercado o restaurante, por ejemplo) debido al desconocimiento del vocabulario francés por un español o del vocabulario del español por un francés.

7. Inventar una breve historia en lengua extranjera o materna sobre una anécdota

4 El Diccionnaire Visuel Google de Gervais (2015) es un ejemplo de diccionario visual colectivo creado a partir de las primeras imágenes que Google propone en las búsquedas de palabras. Se trata a la vez de un proyecto en curso. 
basada en una situación cómica o no tan cómica (en una tienda o supermercado o restaurante, por ejemplo) debido al desconocimiento de las costumbres francesas por un español o de las costumbres españolas por un francés.

Sobre la comida:

8. a. Visitar la web de un hipermercado de France (Carrefour). Visitar la página web del mismo hipermercado en España. Comparar.

b. Hacer lo contrario con un hipermercado español. Qué diferencias se encuentran con los productos, las marcas los precios del mismo producto en ambos países.

9. a. Crear un libro de foto-recetas francesas por regiones en español o bien un libro de foto-recetas españolas en francés.

b. Encontrar listas de platos típicos de diferentes regiones francesas y/o españolas. Por grupos elegir una de esas recetas por región para cocinarla en casa. Hacer una crítica culinaria del plato.

c. Hacer una receta en casa y crear fotos de cada paso. El libro de foto-recetas contendrá la lista de ingredientes escritos y la foto-receta (secuencia de fotos ilustrando la realización del plato).

Sobre la ropa:

10. a. Crear una tienda francesa especializada en ropa para un juego de rol o de simulación. Poner nombre a la tienda y marcas francesas a la ropa.

b. Crear una tienda española especializada en ropa para un juego de rol o de simulación. Poner nombre a la tienda y marcas españolas a la ropa.

c. Visitar la página web de una tienda francesa. Averiguar si la tienda tiene sede en España y mirar si la ropa que vende en España es la misma y si tiene el mismo precio. Anotar el nombre de las prendas. Ampliar el vocabulario temático de la ropa a tu gusto y conforme a tus intereses. Por ejemplo, qué ropa es necesaria en invierno, en primavera, en verano, en otoño, si llueve, si hace frío, para hacer deporte, o para hacer natación...

Otros:

11. Identificar anglicismos entre las palabras más utilizadas en español y en francés. ¿Coinciden algunos, ya sea en el ámbito de la ropa o la alimentación, o en otros ámbitos: tecnología, informática u otros? Buscar en alguna revista de actualidad anglicismos en español y francés, galicismos en español e inglés o hispanismos en francés e inglés.

Si analizamos qué objetivos específicos del MAREP se pueden cubrir con el BILBICAV o algunas de estos modos de explotación, podemos ver en qué medida es pertinente el uso del diccionario complementado con un enfoque plural. El MAREP (Candelier et al., 
2013) está organizado en las siguientes secciones, donde se identifican algunos descriptores de competencias (denominadas "recursos") que pueden pertenecer a la categoría LENGUA ( 1 a 7 ) o a CUltura $(9-14+16)$ o a las dos a la vez de forma combinada (sección 15). El MAREP organiza, además, tanto los Saberes, como el Saber Ser y el Saber Hacer según esta clasificación que se muestra en el Cuadro 3:

\begin{tabular}{lll}
\hline Secciones relativas a Lengua & Secciones relativas a Cultura \\
\hline 1. La lengua como sistema semiológico & 9. Cultura: características generales \\
\hline 2. Lengua y sociedad & 10. Diversidad cultural y diversidad social \\
\hline 3. Comunicación verbal y no verbal & 11. Cultura y relaciones interculturales \\
\hline 4. Evolución de las lenguas & 12. Evolución de las culturas \\
\hline $\begin{array}{l}\text { 5. Pluralidad, diversidad, multilingüismo y } \\
\text { plurilingüismo }\end{array}$ & 13. La diversidad de las culturas \\
\hline $\begin{array}{l}\text { 6. Semejanzas y diferencias entre las len- } \\
\text { guas }\end{array}$ & 14. Semejanzas y diferencias entre culturas \\
\hline \begin{tabular}{l} 
7. Lengua y “adquisición/aprendizaje” \\
\hline
\end{tabular} & 15. Cultura, lengua e identidad \\
\hline
\end{tabular}

Cuadro 3. Secciones del MAREP (Candelier et al., 2013).

En el Cuadro 4 se seleccionan algunos de los "recursos" (o descriptores de competencias) del MAREP donde un enfoque plural es cuanto menos necesario por la necesaria presencia de al menos dos lenguas o dos culturas para ejemplificar y visualizar el saber. A modo ilustrativo, podemos ver los primeros descriptores del MAREP en relación con el SABER para la Sección I. La lengua como sistema semiológico. El BILBICAV y algunos de los modos de explotación pedagógica indicados más arriba facilitarían la enseñanza-aprendizaje de dichos objetivos pedagógicos como se indica.

\begin{tabular}{ll}
\hline \multicolumn{2}{c}{ Recursos } \\
Los SABERES \\
Sección I. La lengua como sistema \\
semiológico.
\end{tabular}


K1.2. Saber que la relación entre las pala- En especial, gracias a la imagen de tipo foto, bras y sus referentes (la realidad a la que se o por los mapas conceptuales. refieren) entre el significante (la palabra, la También por la presencia de distintas acepestructura, la entonación) y el significado es ciones para cada palabra. A diferencia de los a priori absoluta. diccionarios estrictamente visuales.

K1.2.1 Saber que incluso las onomatopeyas, Por la presencia prevista de onomotopeyas, en las que existe una relación estrecha entre por ejemplo, en relación con COMER: $\mathrm{mmm}$, palabra y referente, conservan una parte de ñam-ñam (español), miam o miam-miam arbitrariedad y varían de una lengua a otra. (francés).

K1.2.2. Saber que dos palabras de forma blouse (FR) 'bata'

idéntica/que se parecen en lenguas diferen- blusa (ESP) 'chemisier'/'blouse' tes, no tienen necesariamente el mismo significado.

K1.2.3. Saber que las categorías gramatica- En especial mediante ejemplos en este nivel les no son un calco de "la" realidad sino una A1:

manera de organizarla en una lengua. $\quad-J$ Jai pris mon petit déjeuner. Me he tomado el desayuno.

\begin{tabular}{ll}
\hline K1.2.3.1. Saber que no hay que confundir & $\begin{array}{l}\text { Presencia de información gramatical de } \\
\text { género gramatical y sexo. }\end{array}$ \\
& base y de ejemplos de uso de la palabra: \\
& le gilet $(\mathrm{m}$.$) frente a la chaqueta (\mathrm{f})$. \\
\hline
\end{tabular}

Cuadro 4. Propuesta de explotación del BILBICAV para el desarrollo de los recursos relativos a los Saberes (Sección 1) previstos en el MAREP.

Como cabía esperar, este diseño de diccionario bilingüe y bicultural por sí solo no permite abordar el desarrollo de toda la competencia plurilingüe y pluricultural (Candelier et al., 2013) así como de las componentes de la competencia cultural que Puren (2015) plantea en su modelo. Es necesaria pues una explotación adecuada. Así, en la tabla siguiente podemos ver en qué medida la metodología permite abordar estas competencias: pluricultural (vivir con), metacultural (hablar sobre), transcultural (traducir, reconocer), intercultural (hablar con), co-cultural (actuar con). 


\section{Componentes de la competencia cultural}

(Puren, 2015) competencia pluricultural
(capacidad para convivir en
harmonía en una sociedad mul-
ticultural con personas parcial o
totalmente diferentes)

competencia intercultural

(capacidad para identificar los malentendidos o la falta de entendimiento en primeros contactos o contactos puntuales)

competencia transcultural

(capacidad para reconocer en los textos clásicos un fondo común, lo humano más allá de la diversidad de manifestaciones culturales)

\section{Explotación del BILBICAV}

vivir con: es la competencia quizás más amplia y, para su desarrollo, el BILBICAV puede mostrar mejor la especificidad de los modos de vida detrás de las palabras, en concreto, en aspectos como la comida y la ropa (las fotos permiten visualizar mejor los referentes reales y acercarnos a otras representaciones mentales)

hablar con: el BILBICAV mejora la comprensión del trasfondo cultural de las palabras, en especial, por mostrar la especificidad de los modos de vida detrás de las palabras, en concreto, en aspectos como la comida y la ropa (horarios, tipos de contenidos de las comidas, ingredientes específicos..., costumbres en la mesa) traducir (reconocer): de momento, el BILBICAV por sí solo no proporciona elementos para trabajar esta competencia en su primer desarrollo, aunque merece la pena explorar en el futuro esta dimensión. Quizás sea más difícil en el ámbito del nivel A1 del MCER, pero podrían quizás destacarse ciertos elementos que podrían considerarse más universales ${ }^{5}$, por ejemplo "europeos", ampliando la comparación de lenguas culturas con otras, por ejemplo cultura inglesa (Reino Unido) o alemana (Alemania) o italiana (Italia). Por otro lado, se puede hablar sobre el fondo greco-latino común en las sociedades europeas, pero también de las culturas mediterráneas o bien de la presencia del inglés en la cultura actual en casi todos los países-lenguas (préstamos), de cuentos populares, canciones y refranes cercanos. Estos elementos no se pueden todavía encontrar en el nivel A1 o en las temáticas que hemos seleccionado, pero pueden tener cabida. La "homogeneización" de las imágenes en google de la que hemos hablado, en cambio, sí se puede tener en cuenta. Buscar lo común y articularlo con lo diferente puede ser un objetivo de la "metodología" que sugerimos en el BILBICAV. Estructura de comida europea vs. estructura de comida oriental...

competencia metacultural (ca- hablar sobre: en el caso del BILBICAV nos parece que pacidad para hablar sobre la las imágenes, en especial de tipo foto, los mapas concepcultura a partir de los conoci- tuales propuestos o por ampliar pueden ser un buen punto mientos o crear nuevos concep- de partida. Además, las notas culturales permiten acceder tos a partir de la observación, a algunos aspectos contrastivos.

lectura de textos auténticos...)

5 Para Forestal (2008) lo transcultural hoy día es un tema que ha de ser discutido en profundidad, frente a la neutralidad y la tentación relativista que se da en la Didáctica de Lenguas y además en su relación con los otros componentes. Para ella, lo transcultural en DLC puede ponerse en relación con la mundialización, ser cosmopolita y multilingüe, ahora bien, también con la aculturación, por la homogeneización de la cultura. En este sentido, Forestal prefiere la variedad a la homogeneización. 


\section{Componentes de la competencia cultural} (Puren, 2015)

\section{Explotación del BILBICAV}

competencia co-cultural (ac- actuar con: la metodología explícita del BILBICAV, potuar con el otro de manera que dría llevar a concebir otros BILBICAV como proyectos se consiga un proyecto vital con centros escolares de intercambio, como preparación conjunto; creación de una cultu- para un intercambio entre centros hermanados, o simplera compartida). mente aprendiendo en TANDEM... y en combinación, por tanto, con otras actividades más concretas de tipo intercultural de largo recorrido (como indica Puren, la competencia co-cultural implica más que un simple encuentro, se trata de crear algo conjuntamente para un objetivo común compartido). Es una de las propuestas pedagógicas que acompañan este BILBICAV.

Cuadro 5. Explotación del BILBICAV según los distintos componentes de la competencia cultural explicitados por Puren (2015).

\section{Conclusiones}

Hemos podido mostrar que la concepción y diseño de este diccionario constituye un ejercicio de aplicación que lleva hasta sus últimos términos un enfoque lingüístico-pragmático a partir del concepto de relatividad lingüística y de un enfoque cultural que parte del concepto de relatividad cultural. En el marco de la Didáctica del Plurilingüismo, el diccionario lleva también hasta el extremo un enfoque didáctico "plural" y, por último, como recurso digital, es un recurso "multimodal" (que tiene en cuenta distintos perfiles de aprendizaje y un grado importante de accesibilidad) adaptado a su objetivo de poner de manifiesto las diferencias lingüísticas entre el español y el francés, y las diferencias culturales entre España y Francia, de manera que pueda percibirse desde distintos planos: visual, textual, auditivo, así como con visiones globales o explicaciones más particulares de los contrastes y posibles equivalencias lingüísticas y culturales.

Hemos podido también constatar que el recurso lexicográfico en sí no es siempre suficiente para poder abordar los distintos objetivos del MAREP (Marco de Referencia para los enfoques plurales) que permiten desarrollar ampliamente la competencia plurilingüe y pluricultural, sino que es necesario también tomar conciencia de los presupuestos de la metodología o enfoque didáctico "plural”. Por ello, el diccionario añade una serie de sugerencias de explotación que lo completan en este sentido.

Por otro lado, dado que explicitamos la metodología de elaboración del diccionario, creemos que podemos hablar prácticamente de una metodología BILBICAV para la elaboración de diccionarios bilingües y biculturales, reproducible y transferible a otras áreas temáticas, a otros pares de países o a otros pares de lenguas. De hecho, una de nuestras propuestas 
de explotación del BILBICAV es emular el formato para contextos educativos específicos para ganar en pertinencia y en significatividad.

Por último, entre las actitudes necesarias para poder poner en práctica un enfoque plural de cara a desarrollar la competencia plurilingüe y pluricultural en el aula de lengua extranjera, no solo con este recurso en particular, se encuentra una toma de conciencia de la relatividad cultural por parte del profesor. En el contexto escolar, ¿cuánto conocimiento y respeto hay a la variedad lingüística y cultural que existe del propio país (distintas lenguas y dialectos, distintas culturas), o incluso "dentro de la misma aula"?

Es bueno que el cambio de paradigma o de visión y percepción parta de la realidad más próxima, pero, a veces, la dificultad para admitir y aceptar esta variedad cultural interna a un país se puede ver beneficiada por la toma de conciencia de un contraste aún mayor con una lengua-cultura más lejana, lo que permite volver después sobre la especificidad de nuestra cultura y de la diferenciación dentro de las distintas regiones y áreas lingüísticas y culturales del propio país, de la propia región, de la propia aula.

\section{Referencias bibliográficas}

A.A.v.v. 2006. Plan curricular del Instituto Cervantes: Niveles de referencia para el español. Madrid, Instituto Cervantes: <https://cvc.cervantes.es/ensenanza/biblioteca_ele/plan_curricular/> [11/06/2020].

Arnaud, Philippe. 1992. Vocabulaire de la ville expliqué et illustré. Paris, La Découverte.

AtTruiA, Francesco. 2010. "De l'approche lexiculturelle des dictionnaires monolingues: le nouveau Petit Robert 2010, version électronique" in Éla, Études de linguistique appliquée, n 157, 9-22. DOI: https://doi.org/10.3917/ela.157.0009

BeAcCo, Jean-Claude \& Rémy PORQUIER. 2007. Niveau A1 pour le français. Un référentiel. Paris, Didier.

BeAcCo, Jean-Claude \& Rémy PORQUIER. 2008. Niveau A2 pour le français. Un référentiel. Paris, Didier.

BEACCO, Jean-Claude et al. 2011a. Niveau B1 pour le français. Un référentiel. Paris, Didier.

BEACCO, Jean-Claude et al. 2011b. Niveau B2 pour le français. Un référentiel. Paris, Didier.

Byram, Michael et al. 2002. Developing the Intercultural Dimension in Language Teaching: A Practical Introduction for Teachers. Estrasburgo, Council of Europe.

Candelier, Michel \& Véronique CAstellotti. 2013. "Didactique(s) du(des) plurilinguisme(s)" in Simonin, Jacky \& Sylvie Wharton (dirs.). Sociolinguistique du contact. Dictionnaire des termes et concepts. Lyon, ENS Editions, 179-221. DOI: https://doi. org/10.4000/books.enseditions. 12435

CAndelier, Michel et al. 2013. Marco de Referencia para los Enfoques Plurales de las 
Anales de Filología Francesa, n. ${ }^{\circ}$ 29, 2021

CONCIENCIA LINGÜÍSTICA Y CULTURAL A TRAVÉS DEL LÉXICO Y LA IMAGEN: DICCIONARIO...

Lenguas y de las Culturas (MARAP). Estrasburgo, Consejo de Europa: <http://carap.ecml.at/ Portals/11/documents/MAREP_Cast_vers5def_08.pdf $>$ [11/06/2020].

Consejo de Europa. 2002. Marco común europeo de referencia para las lenguas: aprendizaje, enseñanza, evaluación. Madrid, Anaya/MECD/Instituto Cervantes.

Conseil de L'Europe. 2018. Cadre européen commun de référence pour les langues. Volume complémentaire. Estrasburgo, Consejo de Europa: <https://rm.coe.int/cecr-volume-complementaire-avec-de-nouveaux-descripteurs/16807875d5> [11/06/2020].

Coste, Daniel, Moore, Danièle \& Geneviève Zarate. 1997[2009]. Compétence plurilingue et pluriculturelle. Estrasburgo, Conseil de l'Europe.

FEnNer, Anne-Brit \& David NEWBY. (eds.) 2002. Réflexion sur la conception de supports dans les manuels en Europe: la mise en oeuvre des principes d'authenticité, d'autonomie de l'apprenant et de sensibilisation à la culture Estrasburgo, ECML. $<$ https://www.ecml.at/Portals/1/documents/ECML-resources/pub2002FFennerNewby. pdf?ver $=2018-04-19-093338-620>$ [11/06/2020].

Ferrara, Alice. 2009. "Le dictionnaire d'un pays, le pays d'un dictionnaire" in Éla, no 154 , 191-203. DOI: https://doi.org/10.3917/ela.154.0191.

Forestal, Chantal. 2008. "L'approche transculturelle en didactique des langues-cultures: une démarche discutable ou qui mérite d'être discutée?" in Éla. n 152, 393-410. DOI: https://doi.org/10.3917/ela.152.0393.

Galisson, Robert. 1995. "Où il est question de lexiculture, de cheval de Troie et d'impressionisme" in Éla, no 97, 5-14.

GervaIs, Bertrand. 2015. "DVG. Dictionnaire Visuel Google": <https://dictionnairevisuelgoogle.tumblr.com/> [13/03/2021].

Grosjean, François. 2015. "Bicultural bilinguals" in International Journal of Bilingualism, 19(5), 572-586: <https://www.francoisgrosjean.ch/bilin_bicult/9\%20Grosjean.pdf> [13/03/2021].

Grosjean, François. 2018. "Être bilingue aujourd'hui" in Revue française de linguistique appliquée, $\mathrm{n}^{\mathrm{o}}$ 23(2), 7-14: <https://www.francoisgrosjean.ch/bilin_bicult/28\%20Grosjean. pdf $>[13 / 03 / 2021]$.

Guillen, Carmen. 2003. 'Une exploration du concept 'lexiculture' au sein de la Didactique des Langues-Cultures" in Didáctica (Lengua y Literatura), n 15, 105-119.

Leroyer, Patrick \& Henning Bergenholtz. 2013. "Métalexicographie culturelle, fonctions lexicographiques et finalité pragmatique" in Éla, $\mathrm{n}^{\circ} 170,153-178$. DOI: https://doi. org/10.3917/ela.170.0153.

Muller, Catherine. 2012. "La photographie, un outil pour communiquer en classe de langues" in Recherche et pratiques pédagogiques en langues de spécialité, vol. XXXI, n 1 . DOI: https://doi.org/10.4000/apliut.2224.

Neuner, Gerhard et al. 2003. La compétence interculturelle. Estrasburgo, C. de l'Europe.

Proulx, Christelle. 2016. "Le façonnement du visible. Les dictionnaires visuels de Google 
et la 'pertinence' des résultats" in Captures. Figures, théories et pratiques de l'imaginaire 1(2), DOI: https://doi.org/10.7202/1059817ar Version enrichie sur: <http://revuecaptures. org/node/470> [13/03/2021].

Puren, Christian (s.f.). "Dossier 1: Les trois perspectives constitutives de la DLC": <https:// www.christianpuren.com/cours-la-dlc-comme-domaine-de-recherche/dossier-n-1-les3-perspectives-constitutives-de-la-dlc/> [11/06/2020].

Puren, Christian. 2015. "La compétence culturelle et ses différentes composantes dans la mise en œuvre de la perspective actionnelle: une nouvelle problématique didactique" in Intercâmbio, Revue d'Etudes Françaises, vol. 7, 21-38: <https://www.aplv-languesmodernes. org/spip.php?article1774> [11/06/2020].

REY, Alain. 2005. Dictionnaire culturel du français. Paris, Robert.

Rossignol, Marie-Jeanne. 2000. "Quelle(s) discipline(s) pour la civilisation?" in Revue Française d'Etudes Américaines, no 83, 13-27. DOI: https://doi.org/10.3406/rfea.2000.1791

Sanz Espinar, Gemma. 2004. "El libro bifronte" in SuÁrez, Pilar et al. (eds.). L'autre et soi-même. Madrid, UAM/Ima Ibérica, 445-454.

Sanz Espinar, Gemma. 2020. "Verbos de movimiento en un diccionario bilingüe sintáctico-combinatorio francés-español: TACTICOMB" in Anales de Filología Francesa de la Universidad de Murcia, vol. 28(1), 627-650: <https://revistas.um.es/analesff/article/ view/430691/291671> [11/06/2020].

SANZ EsPINAR, Gemma. 2021. "Las secciones lingüísticas de francés" in MANGADA, Beatriz (ed.) (2021): La Didáctica del francés en Secundaria. Madrid, Paraninfo, 239-278.

Simon, Taryn \& Aaron Swarts. 2012. "Image atlas": <www.image.atlas.org> [13/03/2021]. 
